\title{
A Review of the Impact of Occupational Contact Dermatitis on Quality of Life
}

\author{
Melisa Yi Zhi Lau, ${ }^{1}$ John Anthony Burgess, ${ }^{1}$ Rosemary Nixon, ${ }^{2}$ Shyamali C. Dharmage, ${ }^{1}$ \\ and Melanie Claire Matheson ${ }^{1}$
}

\author{
${ }^{1}$ Centre for Molecular, Environmental, Genetic \& Analytic (MEGA) Epidemiology, School of Population Health, \\ The University of Melbourne, Level 1, 723 Swanston Street, Carlton, VIC 3053, Australia \\ ${ }^{2}$ Occupational Dermatology Research and Education Centre, Skin and Cancer Foundation Inc., \\ Level 1, 80 Drummond Street, Carlton, VIC 3053, Australia
}

Correspondence should be addressed to Shyamali C. Dharmage, s.dharmage@unimelb.edu.au

Received 1 December 2010; Accepted 19 January 2011

Academic Editor: Ting Fan Leung

Copyright (C) 2011 Melisa Yi Zhi Lau et al. This is an open access article distributed under the Creative Commons Attribution License, which permits unrestricted use, distribution, and reproduction in any medium, provided the original work is properly cited.

Occupational contact dermatitis (OCD) is the most common occupational skin disease in many countries. We reviewed the current evidence on how OCD impacts on quality of life (QoL). The three commonly used QoL questionnaires in OCD were the ShortForm Health Survey (SF-36), the Dermatology Life Quality Index (DLQI), and the Skindex. Despite the availability of a variety of validated QoL instruments, none of them is specific to OCD or entirely adequate in capturing the impact of OCD on QoL. Nonetheless, the results of this paper do suggest a significant impact. Use of QoL measures in clinical settings will provide patients with an opportunity to express their concerns and assist clinicians to evaluate the effectiveness of management beyond the clinical outcomes. This paper also highlights the lack of a disease-specific QOL instrument and the importance of developing a validated measure to assess QOL in OCD, enabling comparison across countries and occupational groups.

\section{Introduction}

Occupational contact dermatitis (OCD) has been defined as a pathologic condition of the skin for which occupational exposure can be shown to be a major cause or contributory factor [1]. OCD is relatively common and in many countries, OCD accounts for the majority of cases of occupational diseases [2]. In Australia, the incidence of OCD as reported in 2005 was 2.15 per 10,000 full-time workers per year [3] and internationally, the incidence of OCD ranged from 1.3 to 8.1 per 10,000 full-time workers per year over the past two decades [4].

The two most common types of OCD are allergic contact dermatitis (ACD) and irritant contact dermatitis (ICD). ACD is a delayed-type immunological reaction in response to cutaneous contact with an allergen in sensitised individuals and is diagnosed by patch testing, while ICD results from direct contact with aggravating factors such as wet work, soap, solvents, and heat that triggers the release of inflammatory mediators [2]. No routine clinical testing is available; therefore, the diagnosis is often made by exclusion of allergy in ICD. In the acute condition, the OCD may manifest as itching, redness, scaling, vesiculation, and clustered papulovesicles while fissuring, hyperkeratosis, and lichenification occur in the more chronic state [2].

The impact of OCD is often underestimated because the course of the disease is not life-threatening and minor degrees of OCD are accepted as "part of the job". However, OCD can have profound effects involving the need to change occupation and take prolonged sick leave, as well as limiting leisure activities, interfering with the ability to perform household chores and the necessity to pursue timeconsuming treatment [5]. These all affect the quality of life (QoL).

The prognosis of OCD is poor with almost half of all patients having a condition that does not fully resolve and continues to have an impact on QoL $[6,7]$. The aim of this paper is to evaluate and summarise the current evidence of 
the impact of OCD on QoL and examine the evidence on the sensitivity of the current measures of QoL in OCD.

\section{Quality of Life Measures in OCD}

Over recent years, much emphasis has been placed on measuring the impact of skin diseases on QoL [17]. There has been a change in emphasis away from the traditional clinician-determined method of assessing OCD severity to using the patient's perspective, as assessed by QoL scores [25].

The use of QoL measures provides patients with an opportunity to express their concerns and assist clinicians in their evaluation of the overall effectiveness of management [17]. Generic questionnaires are used to estimate the patient's general QoL in various clinical settings while disease-specific questionnaires concentrate on a particular disease. Dermatology-specific questionnaires describe the effects of particular skin conditions and allow comparison of the impacts of different skin conditions [26]. Table 1 lists some of the many generic [8-16] and dermatologyspecific [17-24] questionnaires that are commonly used in dermatology.

The Short Form Health Survey (SF-36), the most studied and validated QoL instrument, is the predominantly used generic instrument in dermatology [27]. It can be used across different study populations, allowing comparison between diseases [26]. The SF-36 assesses QoL in eight domains: physical functioning, role limitation as a result of physical functioning, bodily pain, general health, vitality, social functioning, role limitation because of emotional difficulties, and mental health, as well as a question about health transition. Along with the eight domains of the SF-36, there are also two summary measures of physical and mental health called the physical component summary (PCS) score and the mental component summary (MCS) score. However, the PCS of SF-36 was found to be less relevant to dermatology patients than the MCS [28]. Other generic QoL instruments have been used infrequently in dermatology over the past decade.

Since its development in 1994, the Dermatology Life Quality Index (DLQI) questionnaire has been used widely in assessing QoL in patients with a skin disease [18]. It consists of ten questions exploring the effect of the skin condition on six domains: symptoms and feelings, daily activities, leisure, work, personal relationships, and treatment. Compared to other dermatology-specific QoL instruments, it is easy to use and has fewer questions, which might reduce the number of missing responses. Although the DLQI has been found to be a valid measure of QoL in dermatology, it may not be very sensitive in detecting small impairments [27].

Skindex, another dermatology-specific instrument, has also been shown to be valid, reliable, and responsive in assessing QoL in dermatology patients [21]. The Skindex measures QoL primarily in three domains: emotions, symptoms, and functioning. Different versions of Skindex can be used depending on the clinical setting. However, interpretation of scores may be difficult as the meaning of the scores is not well documented [27]. A combination of both generic and dermatology-specific QoL instruments has been suggested by previous reviewers $[5,27]$ as the best way to fully capture the effect of dermatological conditions on QoL.

\section{Characteristics of Studies on QOL and OCD}

We identified 11 studies that have investigated QoL in OCD [29-39] and these are summarised in Table 2. The study design and data collection methods varied greatly across these studies. Seven were follow-up studies $[29,31,32,34-$ $36,39]$, of which five were performed retrospectively [29, 31, $34,35,39]$, while four studies were cross-sectional [30, 33, $37,38]$. The study participants were either recruited from dermatology clinics [29-33, 35, 39] or national registries $[34,36-38]$ and the study samples ranged in size from 36 to 560 people. Although the participants in all studies had a clinical diagnosis made at first contact, in only 8 studies were further investigations done to confirm the clinical diagnosis [30-32, 34-37, 39]. Seven of the 11 studies reviewed reported the percentage of participants with atopy, with the figure ranging from $7.1 \%$ to $92.4 \%$ of the study participants [30, $31,34,35,37-39]$. Five studies used the SF-36 or part thereof $[29,33,37-39]$, seven used the DLQI $[29,30,32,33,35,36$, $39]$, and three used the Skindex questionnaire [31, 37, 38]. Eight studies used the combination of a dermatology-specific instrument and either a commonly used generic instrument or a self-developed questionnaire [29-31, 33, 35, 37-39]. One study used a self-developed descriptive questionnaire as the only QOL instrument [34].

\section{Results}

Overall the studies reviewed have shown a reduction in QoL in patients with OCD (Table 2). The mean overall SF-36 score was reported in two studies $[33,39]$. The aggregated score of the PCS in these studies were 45.3 [33] and 52 [39] while the aggregated MCS scores were 46.4 [33] and 51 [39]. The score of the average overall quality of life for the general population is 50 [40], thus both physical and mental components summary scores in patients with OCD were slightly lower than those found in the general population. Two other studies reported the individual domain scores of the SF-36 rather than the summary score $[37,38]$. The vitality domain was the most affected or had the lowest scores in three studies [37-39] while one study found that role limitations as a result of physical difficulty were the most affected domain [33].

Of the seven studies that used DLQI to assess QoL, five reported an overall mean score $[29,32,33,36,39]$. One study reported a small effect of OCD on QoL [39], three found a moderate effect $[29,33,36]$, and one reported a large effect on QoL [32]. The most affected domains in the DLQI were symptoms and feelings $[29,30,33,36,39]$ and work $[29,32,33,35]$. The large variation may relate to different methods of patient selection, such as from referral clinics and workplaces, and duration of followup.

Two out of the three studies that used the Skindex reported the individual domain scores [31,37]. The domain with the highest score in the Soder et al. [37] study was 
TABLE 1: Generic and dermatology-specific quality of life instruments used in occupational contact dermatitis.

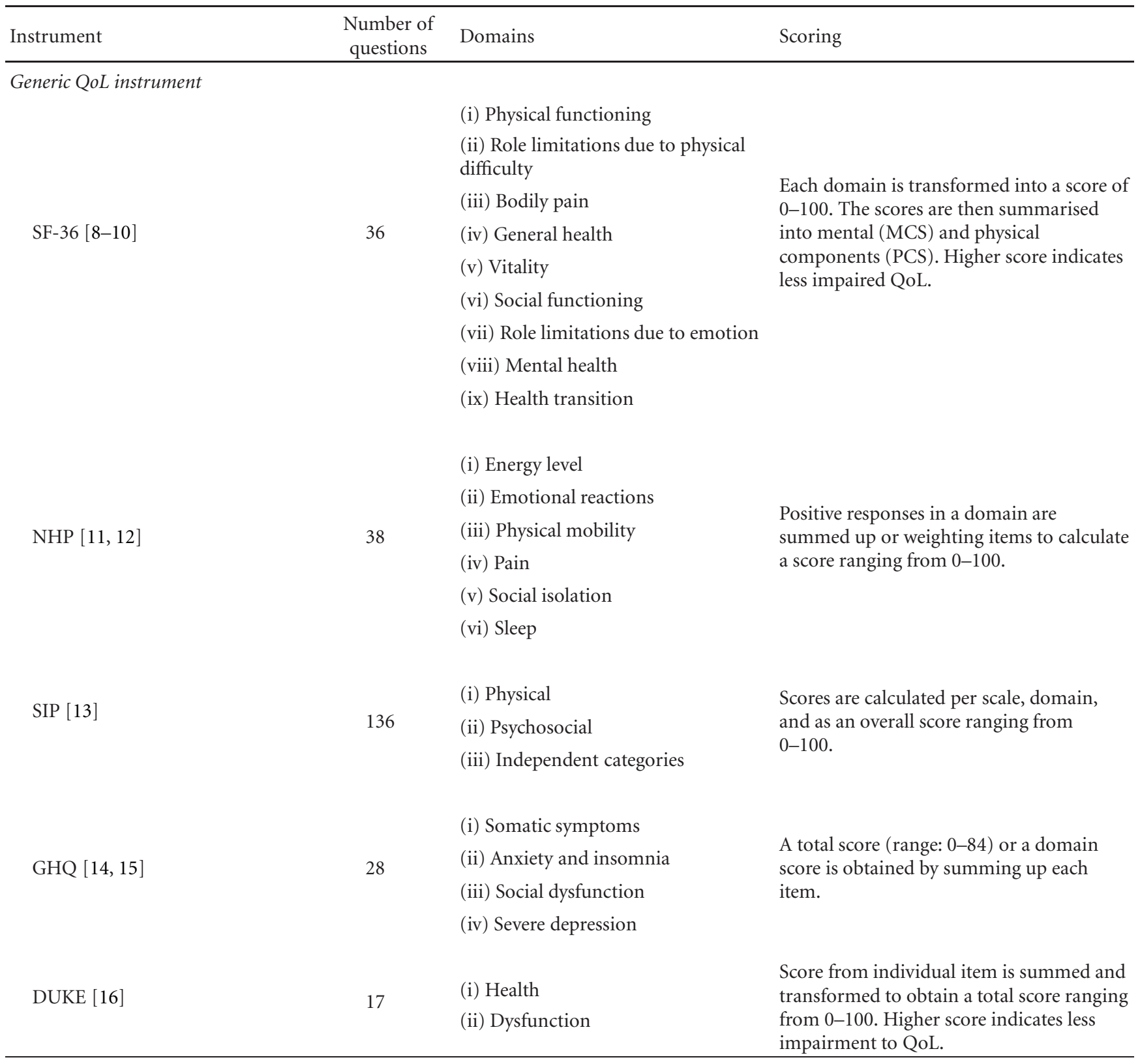

Dermatology-specific QoL instrument

$\begin{array}{ll} & \text { (i) Symptoms and feelings } \\ \text { DLQI }[17,18] & \text { (ii) Daily activities } \\ & \text { (iii) Leisure } \\ & \text { (iv) Work/school } \\ & \text { (v) Personal relationships } \\ & \text { (vi) Treatment } \\ & \\ \text { Skindex }[19-21] & \text { (i) Emotions } \\ & 16,17,29,61 \\ & \text { (ii) Functioning } \\ & \text { (iii) Symptoms }\end{array}$


TABLE 1: Continued.

\begin{tabular}{|c|c|c|c|}
\hline Instrument & $\begin{array}{c}\text { Number of } \\
\text { questions }\end{array}$ & Domains & Scoring \\
\hline DSQL $[22,23]$ & 52 & $\begin{array}{l}\text { (i) Psychosocial } \\
\text { (ii) Activities } \\
\text { (iii) Symptoms }\end{array}$ & $\begin{array}{l}\text { A summary score was calculated by adding } \\
\text { all raw scores from each item. }\end{array}$ \\
\hline DQOLS [24] & 41 & $\begin{array}{l}\text { (i) Physical symptoms } \\
\text { (ii) Daily activities } \\
\text { (iii) Social activities } \\
\text { (iv) Work/school experience } \\
\text { (v) Self perception } \\
\text { (vi) SF-36 vitality subscale } \\
\text { (vii) SF-36 mental health subscale }\end{array}$ & $\begin{array}{l}\text { The score for each domain is calculated } \\
\text { separately, transforming to a score ranging } \\
\text { from } 0-100 .\end{array}$ \\
\hline
\end{tabular}

SF-36: Short-Form Health Survey; NHP: Nottingham Health Profile; SIP: Sickness Impact Profile; WHOQOL: World Health Organisation Quality of Life; GHQ: General Health Questionnaire; DUKE: Duke Health Profile; DLQI: Dermatology Life Quality Index; DSQL: Dermatology-specific Quality of Life; DQOLS: Dermatology Quality of Life Scales.

symptoms (score: 56.9), while Kadyk et al. [31] reported that the emotions domain had the highest score (score: 33.8) when compared to other domains in the questionnaire. Although a higher score generally indicates a greater effect on QoL, the degree of impairment could not be estimated due to absence of reference values or population norm score [40].

The different QoL measures all assess the impact of disease on various domains including symptoms/feelings, effect on work, daily activities and functioning, social/interpersonal activities, and other aspects of QoL. The effects of OCD on these different aspects of quality of life are summarised in Table 3.

4.1. Symptoms and Feelings. OCD frequently invokes strong negative emotions such as frustration, embarrassment, and depression, a reflection that the skin is responsible in large part for an individual's presentation [41]. These negative psychosocial effects were strongly associated with a low or reduced QoL $[31,36]$. Symptoms and feelings were the most affected domains of QoL in nine out of the 11 studies [29, 30, 33-39]. In the DLQI, this domain captures information on symptoms such as itch, sore/pain and stinging, and feelings of embarrassment and self-consciousness over the last week. All three studies that reported individual DLQI domain scores found a very large impact of OCD on symptoms and feelings domain $[29,33,39]$. In one of the reviewed studies, $61 \%$ of participants complained of symptoms and 36\% felt embarrassed about their OCD [30].

The Skindex assesses the symptoms and feelings in two individual domains [21]. Similar to the DLQI, the Skindex captures data on itch, stinging or burning, pain and irritation, as well as emotions like feeling worried, bothered by appearance, being frustrated, embarrassed, and feeling depressed about the skin. One study using Skindex found the symptom domain had the highest reported average score followed by the emotions domain [37] while another study found no significant difference in these two domains when a comparison was made between those with and without occupational ACD [31].

The mental health domain from the SF-36 corresponds to the symptoms and feelings domain in the DLQI and the Skindex. However, its emphasis is more on emotions rather than symptoms. The mental health domain includes questions about feeling nervousness, upset, depressed, calm and peaceful, and happy. The scores were significantly reduced, indicating a negative effect of OCD on mental health, in three studies using the SF-36 [33, 37, 38].

4.2. Work. The impact of OCD is most frequently reported in terms of its effect on work activities. In the SF-36, the effect on work is measured by the domain role limitation caused by physical functioning over the past four weeks. The domain measures the limitation of performing tasks, such as cutting down the amount of time spent on work, accomplishing less work than expected, limitation in the kind of work, and difficulties in performing work. Of the five studies that used the SF-36, two reported significantly reduced domain scores when compared to population norms $[33,38]$ while another two had no difference with the population norms scores $[37,39]$. One study did not report the domain score [29] but found that $45 \%$ of males accomplished less at work and $40 \%$ of females had difficulty in performing work.

Seven studies were using the DLQI which measured the impact of OCD on work impediment and predicament at work over the last week. Only three studies reported the scores [29, 33, 39]. Two found a moderate effect of OCD on work $[29,39]$ while one found a very large impact on work [33]. Other studies found that $20 \%$ of their participants could not work [30], 43\% had interference with work [30], and $39 \%$ reported severe impact on work [32].

In those with OCD, the proportion that had either changed job or made job modifications ranged between $23.1 \%-82 \%[34,35,37]$. An explanation for this large variation may be due to the variety of occupations represented in 


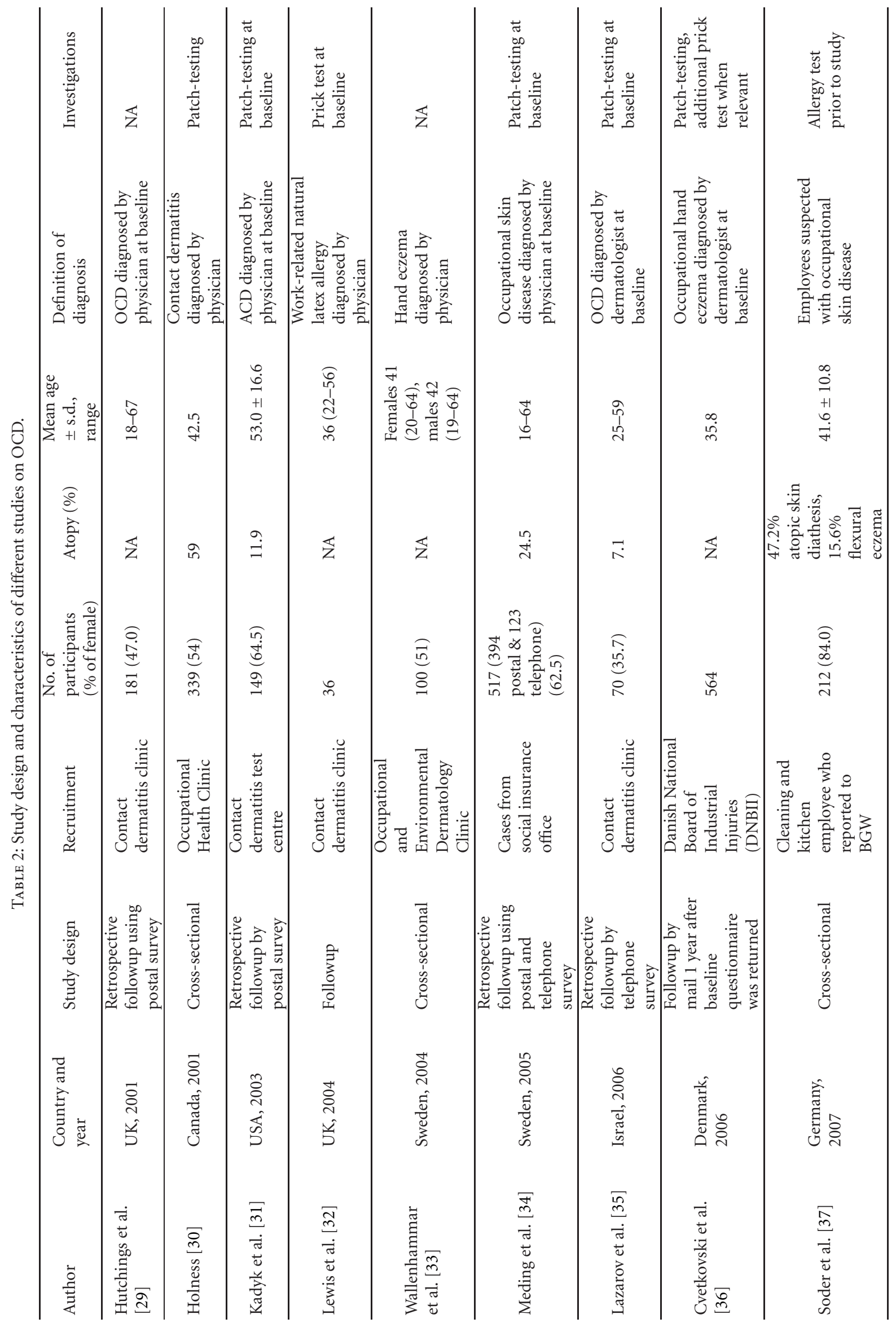




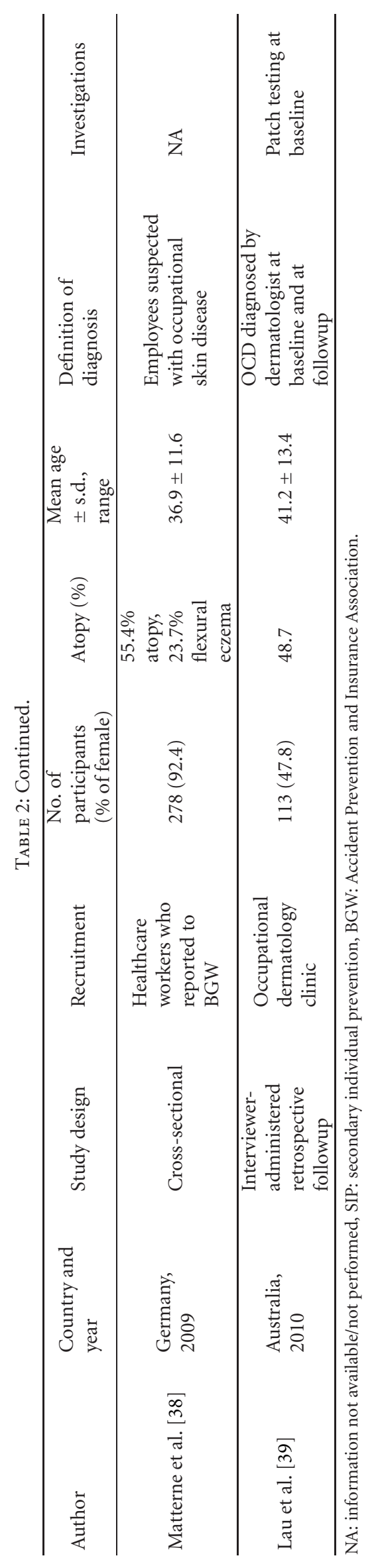




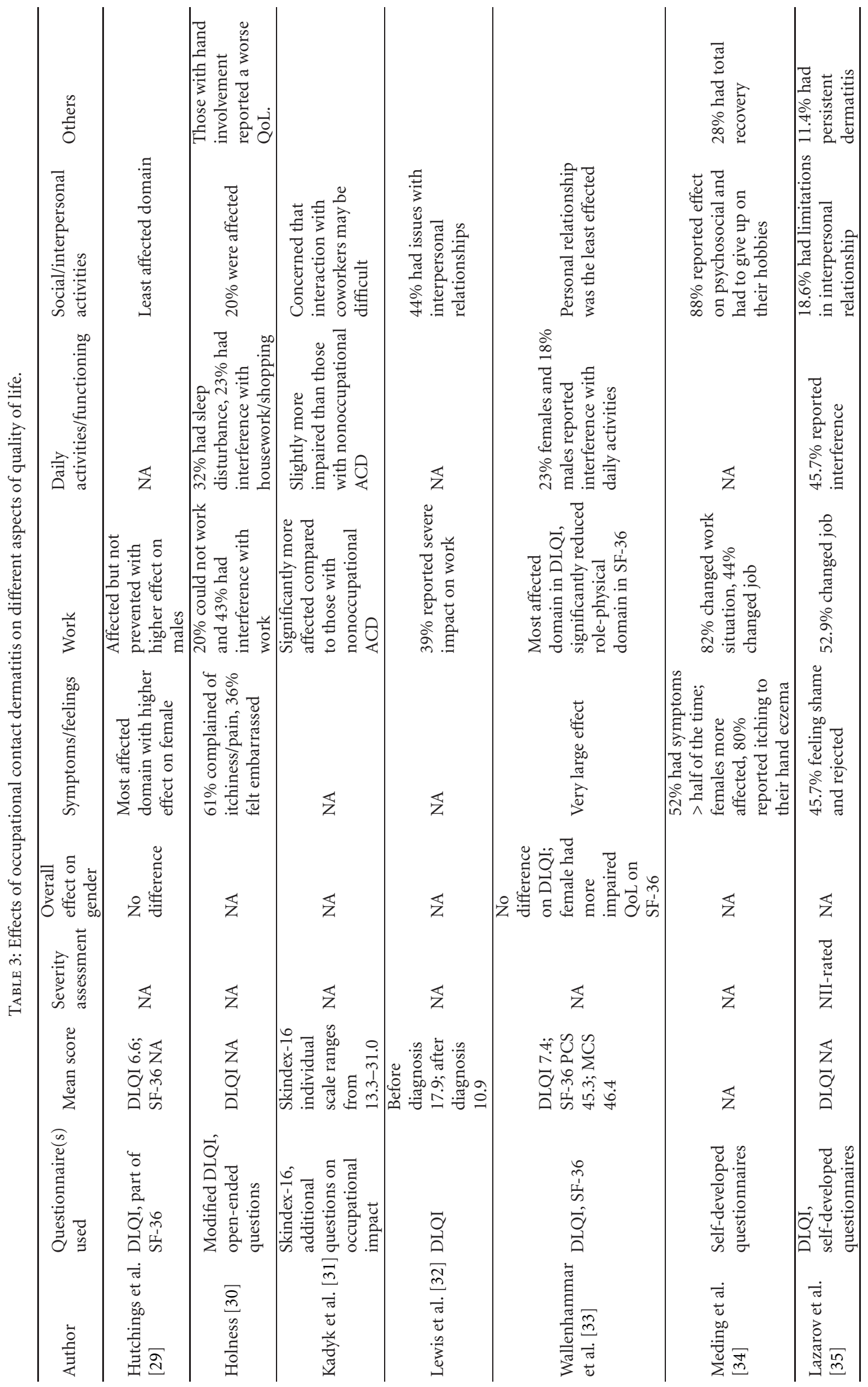




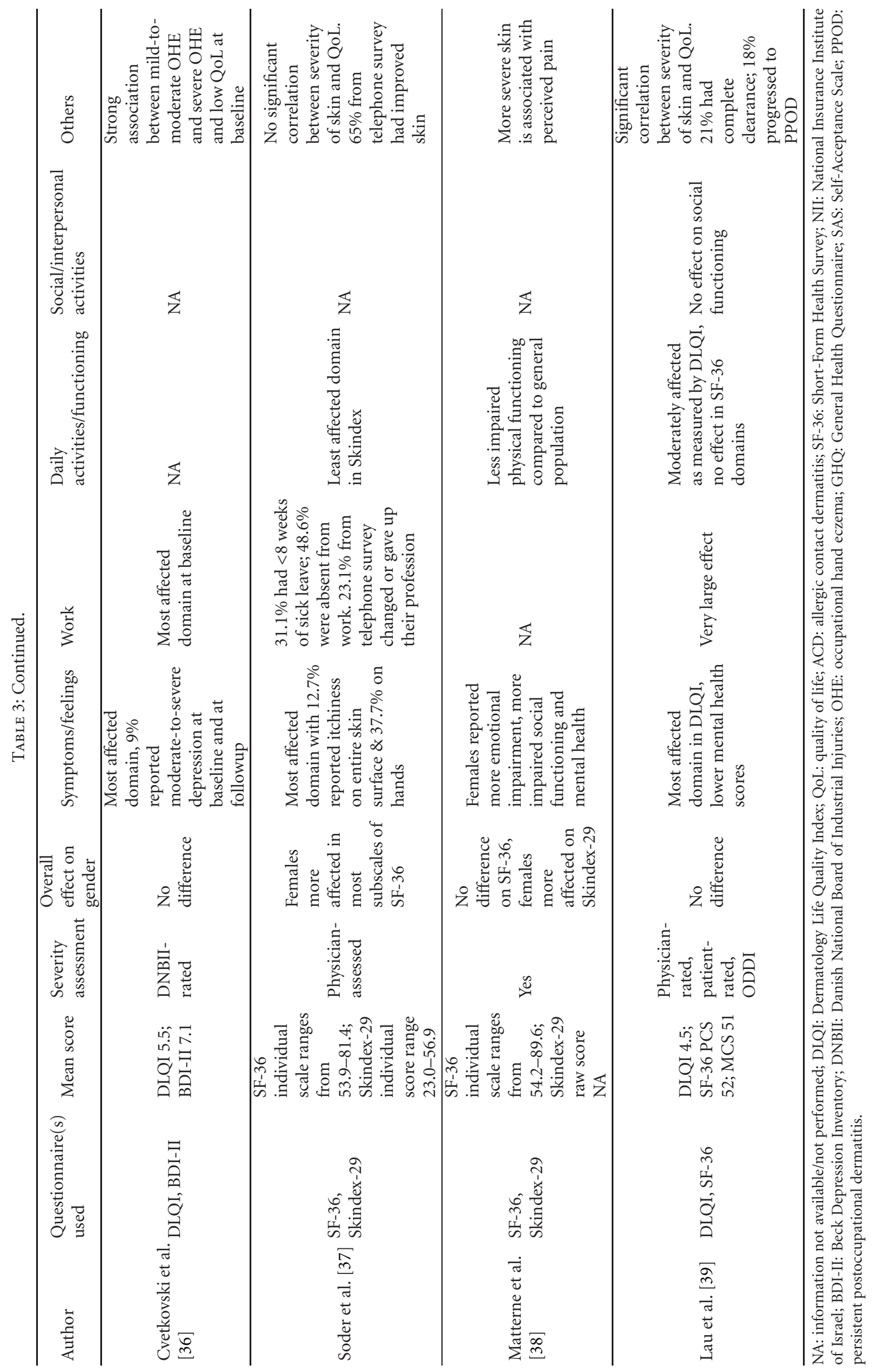


this paper or due to differences in disease duration between studies. The high proportion of people with job modification in the study by Meding et al. [34] might have been due to the use of nonstandardised questions compared to other validated instruments.

4.3. Daily Activities/Physical Functioning. Six studies documented the effect of OCD on daily activities or physical functioning using the DLQI, Skindex, and/or the SF-36. The SF-36 has ten questions about the impact on daily physical functioning such as bathing or dressing, walking, and climbing stairs. When the domain scores were compared to the general population scores, one study found a significant impairment in the physical functioning domain [33], whereas in two other studies, the authors found no effect on physical functioning in OCD patients $[38,39]$.

The daily activities domain is assessed by two questions in the DLQI: interference with housework, shopping or gardening, and influence to the choice of clothing over the last week. Two studies using the DLQI, found a moderate effect on the daily activities domain [33, 39]. Two other studies that used the DLQI but did not document the scores reported that 23\% [30] and $45.7 \%$ [35] of participants had interference in this domain. Holness [30] replaced one question from the DLQI with one related to sleep disturbance and $44 \%$ of patients reported an effect of OCD on sleep. A similar impact on daily activities was reported by Kadyk et al. [31], who found that OCD had a significant impact on daily activities in those with occupational ACD compared to ACD that was not occupational. This study used the Skindex questionnaire which did not further define daily activities. Although most studies reported interference with daily activities or physical functioning, it was often the least affected domain.

4.4. Social/Interpersonal Relationships. OCD can have a considerable impact on social or interpersonal relationships and this domain is assessed by the social functioning domain in the SF-36 and personal relationships domain in the DLQI. The SF-36 assesses this domain by inquiring about the frequency and extent of interference with normal social activities such as visiting friends and relatives. Although this domain score was significantly lower than population norms in two studies $[33,38]$, OCD was not shown to have an effect in interpersonal relationships in one study [39].

Conversely, the DLQI identifies the effect of OCD on sexual difficulties and problems with partners, close friends, or relatives, and three of the reviewed studies found no or little effect on this domain $[29,33,39]$. Some studies reported the proportion instead of domain scores and in these studies, the percentage of OCD patient affected by OCD on their interpersonal relationships ranged from 19 to $44 \%[30,32,35]$. Other studies also found that those with occupational ACD were concerned about interacting with coworkers because of the skin disease [31], while $18.6 \%$ reported difficulty in family relationships, including rejection by a spouse and in some cases, divorce [35].
4.5. Effects on Gender, Age, and Disease Severity. A few studies have found that the effect of OCD on QoL varied between males and females. Several studies reported a higher impact of OCD on QoL in females [33,37], while others reported similar effects in men and women $[29,36,39]$. The apparent greater effect in females may be explained by a higher prevalence of health seeking behaviour by females in general [42], or a larger effect on the mental and social QoL domain in females $[29,34,38]$. Some studies detected a sex difference in QoL using a generic measure $[33,37]$ while other studies detected a difference when a dermatologyspecific instrument was used [38].

Increasing age had been found by one study to increase the impact of OCD on QoL [37] but this was contradicted by three other studies $[29,33,36]$ that found no significant association between age and QoL in patients with OCD. In a Swedish study, a significant interaction between both total PCS and the physical function domain of SF-36 and age was found in females but not males [33]. In a previous paper, the association between age and OCD disappeared when occupation was taken into account in the analysis [2]; therefore, it seemed that age was unlikely to have a major influence on QoL in OCD patients.

Of the included studies, five assessed the severity of OCD [35-39]. A high degree of disease severity was generally associated with a low QoL $[36,38,39]$. No significant correlation was found between severity of skin disease and QoL as determined by SF-36 in two studies $[37,39]$. In contrast, when a dermatology-specific instrument was used, significant correlations between OCD severity and QoL were reported [36, 37, 39]. However, the assessment of the severity of skin disease has been challenging and was not consistent across studies. Some assessments were based on more objective criteria such as morphology, extent of dermatitis, and frequency of flare-up $[35,36,39]$, while others used a simple subjective description to determine severity $[38,39]$.

4.6. Prognosis. Several studies reassessed the participants on followup. The improvement rate varied widely from as little as $21 \%$ to as much as $65 \%[34,37,39]$. Some participants had developed persistent postoccupational dermatitis (PPOD) [43] when reviewed [35, 39]. PPOD has been associated with a reduced ability to work, a negative impact on a financial situation or interference with personal life [44, 45].

\section{Discussion}

OCD-related QoL was found to be reduced in all studies with the areas of highest impact being effects on work and symptoms/feelings. Nevertheless, a large variation between studies was observed in design, patient recruitment, participants' characteristics, assessment of disease severity, and QoL instruments used. This variation in methodology across studies makes comparisons between studies somewhat difficult. Another difficulty in epidemiological studies of OCD is the lack of a clear and standardised definition of OCD. The definitions of OCD used in the reviewed studies have been inconsistent. OCD is not a homogeneous condition: it 
may be ICD or ACD or contact urticaria [2]. Apart from the criteria provided by Mathias in 1989 [46], no other studies had provided a definition for OCD. Our group has previously referred to the lack of standardisation of OCD [4].

The current paper raises several issues to be considered in future research. We found that several studies used both generic and dermatology-specific questionnaires to assess QOL. The main advantage of this is to fully capture the effect of OCD on QOL. Given OCD influences so many different areas of lifestyle, health, economic burden, emotions, and feelings, it is unlikely that the use of either a generic or dermatology-specific instrument will be entirely adequate. To date, there is no validated QoL instrument specific to OCD and the development of a simple yet comprehensive QoL instrument specific to OCD would be of considerable clinical benefit. Currently an international group is investigating the possibility of adding OCD-specific questions to the DLQI and one of the coauthors (RN) of this paper is currently part of a project that is piloting the new questionnaire (personal communication, Dr Päivikki Susitaival).

One important area of research missing from the current literature on QOL in OCD is the evaluation of QoL over time. The assessment of QOL at baseline and then at followup allows the change in physical symptoms and the other components of QOL to be assessed in a validated, consistent manner. Using QoL measures in routine clinical settings will provide patients with an opportunity to express their concerns and assist clinicians in evaluating the effectiveness of management beyond the clinical outcomes. Among the studies included in this paper, only two $[32,36]$ evaluated QoL over time and found an improvement in QOL.

Data on the impact of disease severity on QoL is limited and even the existing literature has assessed disease severity inconsistently across studies, if at all. Furthermore, both objective and subjective measures have been used to evaluate disease severity making interpretation and comparison even more difficult. OCD is primarily a disease of the hands and the existing and validated measures of disease severity $[47,48]$ rely heavily on body surface involvement. Severity scales have been developed for use by the physician in the assessment of hand eczema [49-51] and one has been developed by our group specifically to assess functional limitations as well as severity in OCD $[52,53]$. Using these objective measures of severity in future research would allow for direct comparisons across studies in different countries and occupational groups.

In conclusion, this paper has shown that OCD has a heavy impact on QOL, particularly on work arrangements, which can have important financial and social consequences if not addressed adequately. We would highlight the opportunity for more routine use of QoL measures in patient management. Further studies would benefit from using multiple validated instruments to assess both QOL and disease severity, and specifically a comprehensive QoL instrument specific to OCD, which would enable comparison across countries and occupational groups.

\section{Abbreviations}

$\begin{array}{ll}\text { SF-36: } & \text { Short-Form Health Survey } \\ \text { NHP: } & \text { Nottingham Health Profile } \\ \text { SIP: } & \text { Sickness Impact Profile } \\ \text { WHOQOL: } & \text { World Health Organisation Quality of Life } \\ \text { GHQ: } & \text { General Health Questionnaire } \\ \text { DUKE: } & \text { Duke Health Profile } \\ \text { DLQI: } & \text { Dermatology Life Quality Index } \\ \text { DSQL: } & \text { Dermatology-specific Quality of Life } \\ \text { DQOLS: } & \text { Dermatology Quality of Life Scales. }\end{array}$

\section{References}

[1] C. G. Lane et al., "Industrial dermatoses—a report by the committee on industrial dermatoses of the section on dermatology and syphilology of the American Medical Association," Journal of the American Medical Association, vol. 118, pp. 613-615, 1942.

[2] T. L. Diepgen and P. J. Coenraads, "The epidemiology of occupational contact dermatitis," International Archives of Occupational and Environmental Health, vol. 72, no. 8, pp. 496-506, 1999.

[3] T. Keegel, J. Cahill, A. Noonan et al., "Incidence and prevalence rates for occupational contact dermatitis in an Australian suburban area," Contact Dermatitis, vol. 52, no. 5, pp. 254259, 2005.

[4] T. Keegel, M. Moyle, S. Dharmage, K. Frowen, and R. Nixon, "The epidemiology of occupational contact dermatitis (1990-2007): a systematic review," International Journal of Dermatology, vol. 48, no. 6, pp. 571-578, 2009.

[5] R. Skoet, R. Zachariae, and T. Agner, "Contact dermatitis and quality of life: a structured review of the literature," British Journal of Dermatology, vol. 149, no. 3, pp. 452-456, 2003.

[6] J. Cahill, T. Keegel, S. Dharmage, D. Nugriaty, and R. Nixon, "Prognosis of contact dermatitis in epoxy resin workers," Contact Dermatitis, vol. 52, no. 3, pp. 147-153, 2005.

[7] T. Mälkönen, K. Alanko, R. Jolanki et al., "Long-term followup study of occupational hand eczema," British Journal of Dermatology, vol. 163, no. 5, pp. 999-1006, 2010.

[8] J. E. Brazier, R. Harper, N. M. B. Jones et al., "Validating the SF-36 health survey questionnaire: new outcome measure for primary care," British Medical Journal, vol. 305, no. 6846, pp. 160-164, 1992.

[9] J. E. Ware Jr., M. Kosinski, and B. Gandek, SF-36® Health Survey: Manual \& Interpretation Guide, QualityMetric Incorporated, Lincoln, RI, USA, 2000.

[10] J. E. Ware Jr. and C. D. Sherbourne, “The MOS 36-item shortform health survey (SF-36)-I. Conceptual framework and item selection," Medical Care, vol. 30, no. 6, pp. 473-483, 1992.

[11] S. Hunt, J. McEwen, and S. P. McKeanna, Measuring Health Status, Croom Helm, London, UK, 1986.

[12] P. Plant, J. McEwen, and K. Prescott, "Use of the Nottingham Health Profile to test the validity of Census variables to proxy the need for health care," Journal of Public Health Medicine, vol. 18, no. 3, pp. 313-320, 1996.

[13] M. Bergner and R. A. Bobbitt, "The sickness impact profile: development and final revision of a health status measure," Medical Care, vol. 19, no. 8, pp. 787-805, 1981.

[14] D. P. Goldberg, Manual of the General Health Questionnaire, NFER Publishing, Windsor, UK, 1978.

[15] D. P. Goldberg and V. F. Hillier, "A scaled version of the general health questionnaire," Psychological Medicine, vol. 9, no. 1, pp. 139-145, 1979. 
[16] G. R. Parkerson, W. E. Broadhead, and C. K. Tse, "The Duke Health Profile. A 17-item measure of health and dysfunction," Medical Care, vol. 28, no. 11, pp. 1056-1072, 1990.

[17] A. Y. Finlay, "Quality of life measurement in dermatology: a practical guide," British Journal of Dermatology, vol. 136, no. 3, pp. 305-314, 1997.

[18] A. Y. Finlay and G. K. Khan, "Dermatology Life Quality Index (DLQI) - a simple practical measure for routine clinical use," Clinical and Experimental Dermatology, vol. 19, no. 3, pp. 210216, 1994.

[19] M. M. Chren, R. J. Lasek, S. A. Flocke, and S. J. Zyzanski, "Improved discriminative and evaluative capability of a refined version of Skindex, a quality-of-life instrument for patients with skin diseases," Archives of Dermatology, vol. 133, no. 11, pp. 1433-1440, 1997.

[20] M. M. Chren, R. J. Lasek, L. M. Quinn, and K. E. Covinsky, "Convergent and discriminant validity of a generic and a disease-specific instrument to measure quality of life in patients with skin disease," Journal of Investigative Dermatology, vol. 108, no. 1, pp. 103-107, 1997.

[21] M. M. Chren, R. J. Lasek, L. M. Quinn, E. N. Mostow, and S. J. Zyzanski, "Skindex, a quality-of-life measure for patients with skin disease: reliability, validity, and responsiveness," Journal of Investigative Dermatology, vol. 107, no. 5, pp. 707-713, 1996.

[22] R. T. Anderson and R. Rajagopalan, "Development and validation of a quality of life instrument for cutaneous diseases," Journal of the American Academy of Dermatology, vol. 37, no. 1, pp. 41-50, 1997.

[23] R. Rajagopalan and R. T. Anderson, "Health-related quality of life instrument specific for dermatology," Quality of Life Research, vol. 6, no. 5, p. 11, 1997.

[24] M. Morgan, R. McCreedy, J. Simpson, and R. J. Hay, "Dermatology quality of life scales-a measure of the impact of skin diseases," British Journal of Dermatology, vol. 136, no. 2, pp. 202-206, 1997.

[25] A. Y. Finlay, "Quality of life assessments in dermatology," Seminars in Cutaneous Medicine and Surgery, vol. 17, no. 4, pp. 291-296, 1998.

[26] R. Skoet, R. Zachariae, and T. Agner, "Contact dermatitis and quality of life: a structured review of the literature," British Journal of Dermatology, vol. 149, no. 3, pp. 452-456, 2003.

[27] H. Both, M. L. Essink-Bot, J. Busschbach, and T. Nijsten, "Critical review of generic and dermatology-specific healthrelated quality of life instruments," Journal of Investigative Dermatology, vol. 127, no. 12, pp. 2726-2739, 2007.

[28] E. A. Holm, H. C. Wulf, H. Stegmann, and G. B. E. Jemec, "Life quality assessment among patients with atopic eczema," British Journal of Dermatology, vol. 154, no. 4, pp. 719-725, 2006.

[29] C. V. Hutchings, K. W. Shum, and D. J. Gawkrodger, "Occupational contact dermatitis has an appreciable impact on quality of life," Contact Dermatitis, vol. 45, no. 1, pp. 1720, 2001.

[30] D. L. Holness, "Results of a quality of life questionnaire in a patch test clinic population," Contact Dermatitis, vol. 44, no. 2, pp. 80-84, 2001.

[31] D. L. Kadyk, K. McCarter, F. Achen, and D. V. Belsito, "Quality of life in patients with allergic contact dermatitis," Journal of the American Academy of Dermatology, vol. 49, no. 6, pp. 10371048, 2003.

[32] V. J. Lewis, M. M. U. Chowdhury, and B. N. Statham, "Natural rubber latex allergy: the impact on lifestyle and quality of life," Contact Dermatitis, vol. 51, no. 5-6, pp. 317-318, 2004.
[33] L. M. Wallenhammar, M. Nyfjäll, M. Lindberg, and B. Meding, "Health-related quality of life and hand eczemaa comparison of two instruments, including factor analysis," Journal of Investigative Dermatology, vol. 122, no. 6, pp. 13811389, 2004.

[34] B. Meding, R. Lantto, G. Lindahl, K. Wrangsjö, and B. Bengtsson, "Occupational skin disease in Sweden-a 12-year follow-up," Contact Dermatitis, vol. 53, no. 6, pp. 308-313, 2005.

[35] A. Lazarov, B. Rabin, N. Fraidlin, and D. Abraham, "Medical and psychosocial outcome of patients with occupational contact dermatitis in Israel," Journal of the European Academy of Dermatology and Venereology, vol. 20, no. 9, pp. 1061-1065, 2006.

[36] R. S. Cvetkovski, R. Zachariae, H. Jensen, J. Olsen, J. D. Johansen, and T. Agner, "Quality of life and depression in a population of occupational hand eczema patients," Contact Dermatitis, vol. 54, no. 2, pp. 106-111, 2006.

[37] S. Soder, T. L. Diepgen, M. Radulescu, C. J. Apfelbacher, T. Bruckner, and E. Weisshaar, "Occupational skin diseases in cleaning and kitchen employees: course and quality of life after measures of secondary individual prevention," Journal of the German Society of Dermatology, vol. 5, no. 8, pp. 670-676, 2007.

[38] U. Matterne, C. J. Apfelbacher, S. Soder, T. L. Diepgen, and E. Weisshaar, "Health-related quality of life in health care workers with work-related skin diseases," Contact Dermatitis, vol. 61, no. 3, pp. 145-151, 2009.

[39] M. Y. Z. Lau, M. C. Matheson, J. A. Burgess, S. C. Dharmage, and R. Nixon, "Disease severity and quality of life in a follow up study of patients with occupational contact dermatitis," Contact Dermatitis. In Press.

[40] J. De Korte, M. A. G. Sprangers, F. M. C. Mombers, and J. D. Bos, "Quality of life in patients with psoriasis: a systematic literature review," Journal of Investigative Dermatology Symposium Proceedings, vol. 9, no. 2, pp. 140-147, 2004.

[41] A. Adisesh, J. D. Meyer, and N. M. Cherry, "Prognosis and work absence due to occupational contact dermatitis. Outcome of cases reported to EPIDERM," Contact Dermatitis, vol. 46, no. 5, pp. 273-279, 2002.

[42] C. Rusca, U. Hinnen, and P. Elsner, "Patient's delay'analysis of the preclinical phase of occupational dermatoses," Dermatology, vol. 194, no. 1, pp. 50-52, 1997.

[43] L. M. Wall and K. A. Gebauer, "A follow-up study of occupational skin disease in Western Australia," Contact Dermatitis, vol. 24, no. 4, pp. 241-243, 1991.

[44] S. J. Keogh and D. J. Gawkrodger, "Persistent postoccupational dermatitis: report of five cases," Acta DermatoVenereologica, vol. 86, no. 3, pp. 248-249, 2006.

[45] P. Sajjachareonpong, J. Cahill, T. Keegel, H. Saunders, and R. Nixon, "Persistent post-occupational dermatitis," Contact Dermatitis, vol. 51, no. 5-6, pp. 278-283, 2004.

[46] C. G. T. Mathias, "Contact dermatitis and workers' compensation: criteria for establishing occupational causation and aggravation," Journal of the American Academy of Dermatology, vol. 20, no. 5 I, pp. 842-848, 1989.

[47] J. F. Stalder, A. Taieb, D. J. Atherton et al., "Severity scoring of atopic dermatitis: the SCORAD index. Consensus report of the European Task Force on Atopic Dermatitis," Dermatology, vol. 186, no. 1, pp. 23-31, 1993.

[48] T. Fredriksson and U. Pettersson, "Severe psoriasis-oral therapy with a new retinoid," Dermatologica, vol. 157 , no. 4 , pp. 238-244, 1978. 
[49] P. J. Coenraads, H. Van Der Walle, K. Thestrup-Pedersen et al., "Construction and validation of a photographic guide for assessing severity of chronic hand dermatitis," British Journal of Dermatology, vol. 152, no. 2, pp. 296-301, 2005.

[50] E. Held, R. Skoet, J. D. Johansen, and T. Agner, "The hand eczema severity index (HECSI): a scoring system for clinical assessment of hand eczema. A study of inter- and intraobserver reliability," British Journal of Dermatology, vol. 152, no. 2, pp. 302-307, 2005.

[51] C. Skudlik, M. Dulon, U. Pohrt, K. C. Appl, S. M. John, and A. Nienhaus, "Osnabrueck hand eczema severity index-a study of the interobserver reliability of a scoring system assessing skin diseases of the hands," Contact Dermatitis, vol. 55, no. 1 , pp. 42-47, 2006.

[52] N. Curr, S. Dharmage, T. Keegel, A. Lee, H. Saunders, and R. Nixon, "The validity and reliability of the occupational contact dermatitis disease severity index," Contact Dermatitis, vol. 59, no. 3, pp. 157-164, 2008.

[53] N. Curr, M. C. Matheson, S. Dharmage, and R. Nixon, "Does the occupational contact dermatitis disease severity index correlate with quality of life in patients with occupational contact dermatitis of the hands?" Contact Dermatitis, vol. 62, no. 4, pp. 251-252, 2010. 


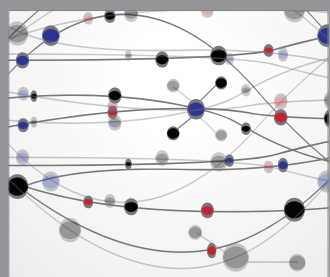

The Scientific World Journal
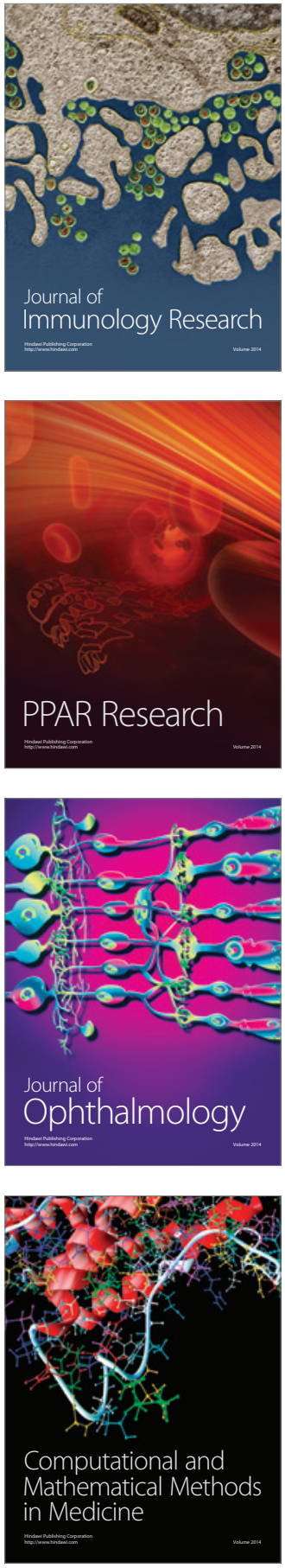

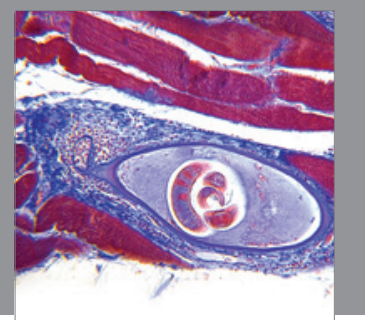

Gastroenterology

Research and Practice
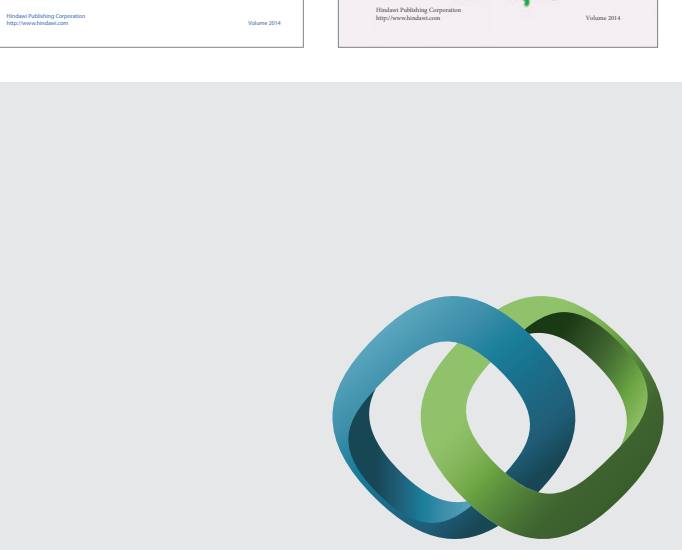

\section{Hindawi}

Submit your manuscripts at

http://www.hindawi.com
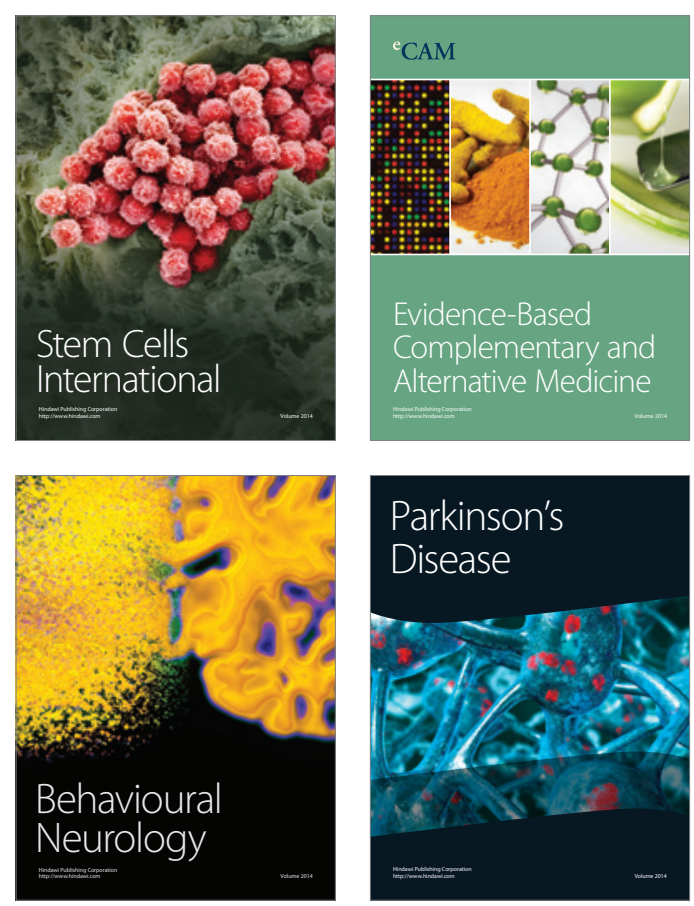

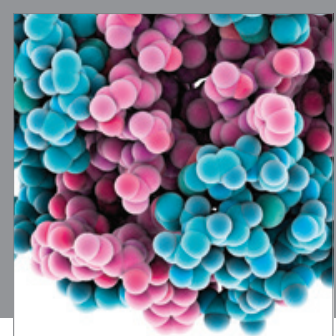

Journal of
Diabetes Research

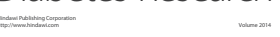

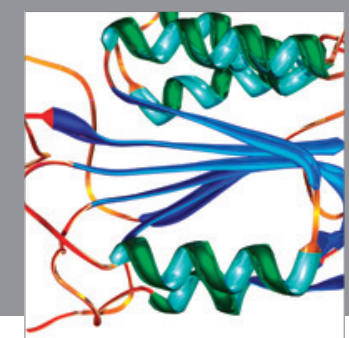

Disease Markers
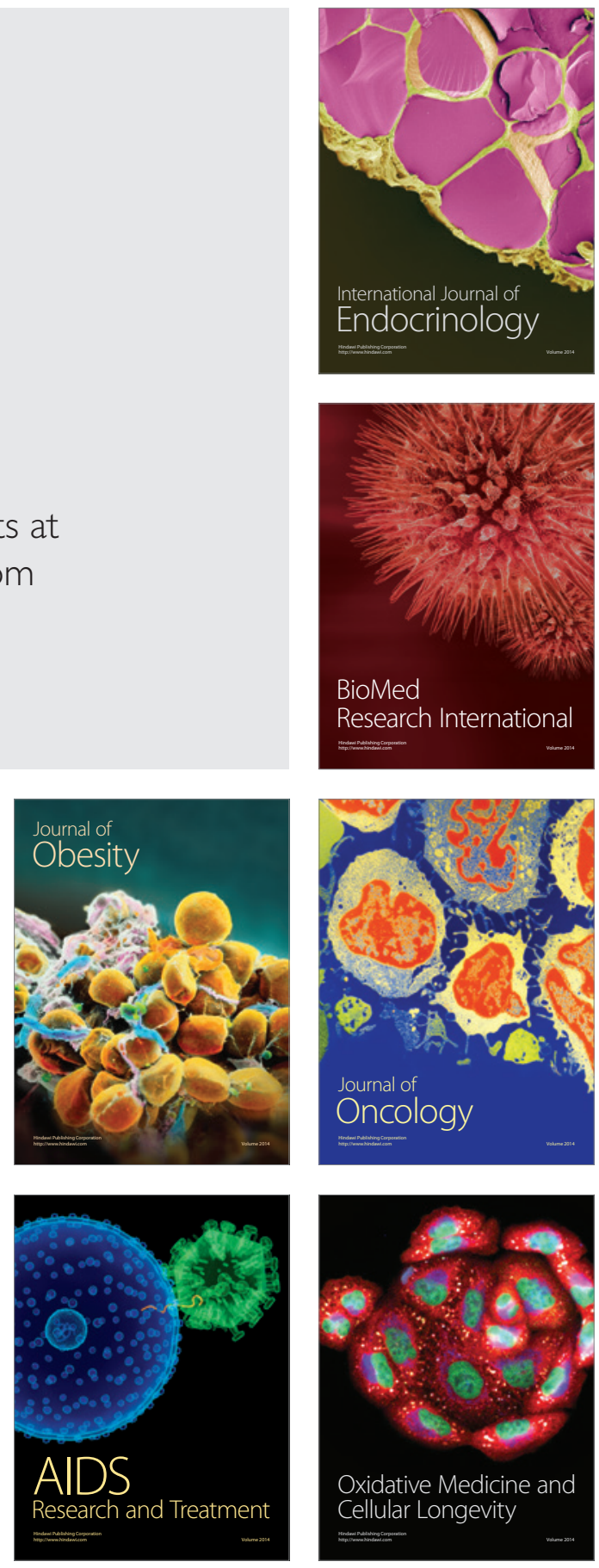